\title{
HYPERPLASTIC GASTRIC POLYPS PRESENTING WITH MASSIVE UPPER GASTRO-INTESTINAL BLEED
}

\begin{abstract}
Karki P*, Ansari J A, Sinha A, Rijal S
\section{ABSTRACT}

A 39 year old man presented with massive upper Gastro-intestinal (GI) Bleed of 4 days duration. There was h/o chronic epigastric pain of 6 months duration. Upper Gl Endoscopy revealed a large polypoid mass of 6 cms $x 5 \mathrm{cms}$ in diameter on anterior wall of body. After resuscitation surgical exploration was done. Biopsy and histopathological examination revealed hyperplastic polyp. Cornual polyp of very large size $(5 \mathrm{~cm} x 6$ cms) with presentation with massive upper gastrointestival bleeding is quite unusual. These polyp are found in people older than 50, usual site is antrum and they usually present with occult blood loss.
\end{abstract}

\section{Key Words: Hyperplastic polyp, upper gastro-intestinal bleeding.}

\section{CASE REPORT}

A 39 year old man presented in emergency with passage of black tarry stool of four days duration along with vomiting of approximately one and half litre of blood 6 hours before coming to emergency. There was no history of NSAID intake in recent past. He had off/on moderate degree pain in the upper abdomen for last 6 months. The pain had no relationship with meals. Pain was localized and had no radiation. There was no past history of vomiting, melaena and haematemesis. He was nonsmoker and nonalcoholic. There was no history of hypertension or diabetes.

On examination he was conscious, pulse 110/minute regular, $\mathrm{BP}=100 / 70 \mathrm{~mm}$ of $\mathrm{Hg}$. Pallor was present. There was no icterus or stigmata of chronic liver disease. His cardiovascular and chest examination was normal. Abdominal examination revealed no organomegaly or ascites. Rectal examination was within normal limits. His Hb was 7.4 gram/dl, Hct 20, TLC 6,200, N 70\%, L30\%, Blood group was A positive. His liver function test, kidney function test as well coagulation profile was normal. After resuscitation upper Gl endoscopy was done which revealed a large polypoid mass of $6 \mathrm{cms} \times 5 \mathrm{cms}$ in diameter on anterior wall of the body of stomach (Fig.1). Biopsy was taken which was reported as hyperplastic polyp - (Fig.2). Patient improved after conservative management. Upper GI endoscopy was repeated for the suspicion of malignancy. Endoscopic and histopathologic picture was same as before and it confirmed to be hyperplastic polyp.

Since the polyp was larger than $5 \mathrm{cms}$ in size and presented as upper gastrointestinal bleeding, surgical exploration was performed. On exploratory laprotomy there was a large sessile polyp of $6 \mathrm{~cm} \times 5 \mathrm{~cm}$ size seen on anterior wall of body of stomach near greater curvature. There was no significant lymph nodes, no evidence of hepatic or peritoneal metastasis seen. Since the size of polyp was larger than $5 \mathrm{~cm}$ in size, keeping the possibility of malignant pathology in mind, distal partial gastrectomy with $5 \mathrm{~cm}$ proximal margin was done. Bilroth II gastrojejunal reconstruction was performed.

Gross examination of specimen showed $6 \mathrm{cms}$ x $5 \mathrm{cms}$ polyp on anterior wall of stomach. Two more polyps less than $1 \mathrm{~cm}$ in size in the pylorus were also present. Histologically these polyps were reported as hyperplastic polyp.

${ }^{\star}$ B.P. Koirala Institute of Health Sciences, Dharan, Nepal.

Address for correspondence : Prof. Dr. Prahlad Karki

B.P. Koirala Institute of Health Sciences, Dharan, Nepal.

Email: prahladkarki@ hotmail.com 
Fig. 1

Fig. 1 : Histopathological picture of hyperplastic gastric polyp.

\section{COMMENTS}

Hyperplastic polyp is the commonest polyp found in the stomach; frequency in more than $85 \%$ of cases. A gastric polyp can be an epithelial polyp, a polypoid gastric carcinoma, a leiomyoma or a carcinoid tumor. Most gastric polyps are found in people older than 50 . They vary in size from 0.1 to $1 \mathrm{~cm}$ in diameter and are generally less than ten in number and having smooth appearance. These polyps do not have prematignant potential. Benign gastric polyps are almost always asymptomatic. They occur throughout stomach but are most often found in the antrum and along gastroenterostomy anastomoses. On microscopic examination they are found to contain hyperplastic glands, often with marked cystic dilation. ${ }^{1,2}$
Patients with benign gastric polyps often complain of epigastric pain, which is perhaps related to the almost invariable inflammatory changes, often with superficial ulcerations of the polyp. Nausea and vomiting occur in $30 \%$ of patients. Erosions at the tips of polyps may cause occult bleeding. ${ }^{3}$ Haematemasis is surprisingly uncommon - probably occurring in fewer than $10 \%$ of such patients. ${ }^{4}$ Occasionally polyps prolapse thorough the pylorus or present at the gastric outlet, causing intermittent obstruction.

Present case has several unique features. It was found in a younger patient, site was body rather than the antrum which is rather unusual, size was larger compared to classical case and lastly it presented with massive upper gastrointestinal bleeding. Upper Gl bleed due to gastric polyps is not a common presentation.

\section{REFERENCES}

1. Luk, G.D. Stomach. In Feldman, M (ed) Colour Atlas of Diagnosis and Treatment in Gastroenterology. London, Science Press, 1994; p.1.

2. Stolte, M. Clinical consequences of endoscopic diagnosis of gastric polyps. Endoscopy 1995:27:32.

3. Mac Donald W C. Gastric Tumours in Gary Gitnic (ed), Principles and Practice of Gastroenterology and Hepatology (Norwalk, Connecticut), $19942^{\text {nd }}$ edition p 208.

4. Elder JB. Benign Gastric Tumours in Diseases of the Gut and Pancreas. J. J Misiewiez, RE Pounder and C W Venables (eds). Black Well Scientific Publications $19942^{\text {nd }}$ editionp 332 . 